\section{Is colonoscopic surveillance reducing colorectal cancer mortality in ulcerative colitis? A population based case control study}

\author{
P Karlén, D Kornfeld, O Broström, R Löfberg, P-G Persson, A Ekbom
}

Division of

Epidemiology,

Institute of

Environmental

Medicine, Karolinska

Institute and

Epidemiologic Unit,

Stockholm County

Council

P-G Persson

Department of Medical Epidemiology, Karolinska Institute, Stockholm, Sweden

A Ekbom

Correspondence to: Dr D Kornfeld, Department of Medical Epidemiology, Karolinska Institute, S-171

77 Stockholm, Sweden.

Accepted for publication 2 December 1997

Keywords: colonoscopic surveillance; colorectal cancer; ulcerative colitis; epidemiology

Death from colorectal carcinoma is the single most important factor for long term mortality in patients with ulcerative colitis (UC). ${ }^{1-9}$ Until the beginning of the 1970 s prophylactic proctocolectomy was the only available option to avoid this outcome. However, the recognition that mucosal precancerous lesions, later referred to as dysplasia, are associated with the development of colorectal cancer in patients with $\mathrm{UC}^{10}$ provided an alternative approach for this group of patients. A prospective endoscopic follow up programme at St Mark's Hospital in London was initiated in $1966 .{ }^{11}$ The rapid evolution of the flexible fibrecolonoscope led to the initiation of endoscopic surveillance programmes at centres in the UK, USA, Swe-

\begin{abstract}
Department of Medicine

P Karlén

O Broström

Department of Surgery, Söder Hospital, Karolinska Institute

D Kornfeld

Department of Gastroenterology, Huddinge University Hospital, Karolinska Institute

R Löfberg

Abstract

Background-Colonoscopic surveillance is a standard procedure in many patients with long standing, extensive ulcerative colitis (UC), in order to avoid death from colorectal cancer. No conclusive proof of its benefits has been presented however. Aims-To evaluate the association between colonoscopic surveillance and colorectal cancer mortality in patients with UC.

Patients-A population based, nested case control study comprising 142 patients with a definite UC diagnosis, derived from a study population of 4664 patients with UC, was conducted.

Methods-Colonoscopic surveillance in all patients with UC who had died from colorectal cancer after 1975 was compared with that in controls matched for age, sex, extent, and duration of the disease. Information on colonoscopic surveillance was obtained from the medical records.

Results-Two of 40 patients with UC and 18 of 102 controls had undergone at least one surveillance colonoscopy (relative risk (RR) $0.29,95 \%$ confidence interval 0.06 to 1.31). Twelve controls but only one patient with UC had undergone two or more surveillance colonoscopies ( RR $0.22,95 \%$ confidence interval 0.03 to 1.74 ), indicating a protective dose response relation. Conclusion-Colonoscopic surveillance may be associated with a decreased risk of death from colorectal cancer in patients with long standing UC.

(Gut 1998;42:711-714)
\end{abstract}

den, and Israel in the 1970 s. $^{12-15}$ Most surveillance programmes have included a total colonoscopic examination at regular intervals combined with multiple biopsy sampling from six to 10 different locations in the large bowel. Such programmes are now widely used in clinical practice and offered to many patients with long standing extensive UC.

The primary aim of these programmes has been to reduce the overall mortality due to colorectal cancer. However, the value of colonoscopic surveillance in this respect has never been evaluated by a randomised controlled trial. For both practical and ethical reasons, it is unlikely that such a trial will ever be carried out.

Previous reports on this subject have mainly been longitudinal descriptive studies without a valid non-surveyed control group. Hence the benefits of colonoscopic surveillance in patients with UC have been questioned. ${ }^{16-18}$ In order to evaluate the impact of colonoscopic surveillance on colorectal cancer (CRC) mortality in patients with UC, a nested case control study was performed using observational data from a large population based cohort of patients with UC.

\section{Materials and methods}

STUDY POPULATION

The study population consisted of all patients with UC diagnosed in Stockholm County between 1955 and $1984^{19}$ and in the Uppsala Health Care Region between 1965 and 1983, ${ }^{20}$ who were 10 years of age or more at the time of UC diagnosis and had at least five years duration of disease since diagnosis. A total of 4664 individuals with a definite diagnosis of UC were derived from a background population comprising approximately three million people living in Stockholm County and in the Uppsala Health Care Region.

The identification of UC patients in both Stockholm County $(n=1547)$ and in Uppsala Health Care Region $(n=3117)$ has been described in detail previously. ${ }^{19-21}$ In short, the identification of patients in Stockholm County was performed manually or partly manually between 1955 and 1969. Since 1969, a computerised register including all hospital admissions in Stockholm County has been used. The medical records of all departments of internal medicine, surgery, paediatrics, and infectious diseases were searched for possible patients with ulcerative colitis using diagnostic criteria in accordance with earlier studies.

In Uppsala the patients with UC were selected from an inpatient register that in- 
Table 1 Characteristics of controls and patients with ulcerative colitis who died from colorectal cancer

\begin{tabular}{lcc}
\hline & Cases n(\%) & Controls n(\%) \\
\hline Sex & $26(65)$ & $52(51)$ \\
$\quad$ Male & $14(35)$ & $50(49)$ \\
$\quad$ Female & $9(22.5)$ & $14(14)$ \\
Age at diagnosis of UC (y) & $12(30)$ & $43(42)$ \\
$\quad<15$ & $11(27.5)$ & $31(30)$ \\
$15-29$ & $8(20)$ & $14(14)$ \\
$30-49$ & $1(2.5)$ & $7(6.9)$ \\
$50+$ & $9(22.5)$ & $29(28.4)$ \\
Extent at diagnosis & $23(57.5)$ & $48(47.1)$ \\
Proctitis & $7(17.5)$ & $18(17.6)$ \\
$\quad$ Left-sided & & \\
Total &
\end{tabular}

Table 2 Colonoscopy surveillance in patients and controls

\begin{tabular}{lccll}
\hline $\begin{array}{l}\text { Surveillance } \\
\text { colonoscopy }\end{array}$ & No of patients & No of controls & Relative risk & $95 \%$ CI \\
\hline $\begin{array}{l}\text { Never } \\
\text { Ever }\end{array}$ & 38 & 84 & 1.0 & Reference \\
& 2 & 18 & 0.29 & 0.06 to 1.31 \\
Never & 38 & 84 & 1.0 & Reference \\
1 & 1 & 6 & 0.43 & 0.05 to 3.76 \\
$2+$ & 1 & 12 & 0.22 & 0.03 to 1.74 \\
\hline
\end{tabular}

CI, confidence interval.
CONTROLS

For each patient the aim was to select three controls matched individually by age at diagnosis (plus or minus five years), duration of disease, extent of disease at diagnosis, and sex. Furthermore, the controls had to be alive at the time of death of the patient and to have some part of the colon intact five years prior to the diagnosis of the cancer of the patient; this gives colonoscopic surveillance the opportunity to exert a possible protective effect. Due to these strict criteria, the control group was confined to 102 of 120 individuals. Table 1 shows the characteristics of the patients and controls.

\section{ASSESSMENT OF SURVEILLANCE}

The medical records for the patients and controls were scrutinised in a uniform manner. Specific information about exposure to colonoscopic surveillance was collected until the date of cancer diagnosis. Only colonoscopies with multiple biopsy specimens from all parts of the colon, performed within the frame of a surveillance programme, were taken into account. Index colonoscopies or colonoscopies performed due to any clinical signs or symptoms were excluded. If the medical records did not clearly indicate that the colonoscopy was conducted as a cancer prophylactic measure the procedure was excluded.

\section{STATISTICAL METHODS}

The association between colonoscopic surveillance and CRC mortality was analysed by the relative risk obtained by the odds ratio. Matched analyses were performed using conditional logistic regression analyses. The estimated standard deviations of the regression coefficient estimates were used to assess 95\% confidence limits. ${ }^{24}$

\section{Results}

Forty patients who died from colorectal cancer and 102 matched controls were analysed. All were diagnosed as having total or extensive (inflammation reaching at least proximal to the hepatic flexure) colitis.

Two of 40 patients and 18 of 102 controls had undergone at least one surveillance colonoscopy (relative risk (RR) 0.29 , 95\% confidence interval 0.06 to 1.31 ) (table 2). Twelve controls but only one patient had undergone two or more surveillance colonoscopies (RR $0.22,95 \%$ confidence interval 0.03 to 1.74 ), indicating a protective dose response relation (table 2). Ten of 102 controls (10\%) underwent colectomy within five years prior to diagnosis of the cancer of the patient.

\section{Discussion}

The optimal study design to show the effect of colonoscopic surveillance on CRC mortality is a prospective trial. Such a trial would include randomisation, and have death from colorectal cancer as the end point. However, practical problems, as noted above, together with ethical considerations, the need for large number of patients, and the substantial length of follow up required indicate the difficulties involved in 
such a study. Thus, any evaluation has to be done through analytical observation studies using retrospective data.

This is the first study to implement established case control methodology in order to assess the benefit of surveillance with colonoscopy in patients with UC. The main finding, although not statistically significant, indicates that colonoscopic surveillance may have a protective effect against death from colorectal cancer. This protective effect is even more pronounced if the patients underwent two or more surveillance colonoscopies, indicating a protective dose response relation. In spite of the fact that the study is derived from a large cohort of 4664 patients with UC within a population of three million people, there is a lack of statistical power as only 40 patients died from CRC. Furthermore, less than $20 \%$ of the controls had a history of colonoscopic surveillance, a proportion most likely reflecting the clinical practice in Sweden in the 1970s and the early 1980s.

The lack of information in patients and controls of potential confounding factors is another concern. Pharmacological treatmentthat is, sulphasalazine, which has been shown to decrease the risk of CRC, ${ }^{25}{ }^{26}$ constitutes such a potential confounding factor. Patients with active disease are likely to be more frequently in contact with the health care system and thus undergo more frequent pharmacotherapy, but could also be more likely to be enrolled in a surveillance programme, thus creating bias.

The assessment of exposure to surveillance in this study was made without blinding for case control status which could introduce differential misclassification of exposure. In order to control for this possible bias, strict criteria for what could be considered surveillance colonoscopies were set up. Only colonoscopies performed with the intention of cancer surveillance were included, thus excluding index colonoscopies and those being made due to clinical symptoms or signs.

The major strength of this study is that it is population based and that links with the Swedish Cancer Register and the Swedish Cause of Death Register makes a non-differential classification of outcome possible with both high specificity and high sensitivity. The matching criteria also eliminated some other possible confounders.

One remaining uncertainty is to what extent our results are valid if all known patients with extensive UC were enrolled in a surveillance programme, especially as there are reasons to believe that colonoscopic surveillance today is a more common procedure in these patients than in previous years. The intricate problem of external validity, which has been taken for granted in hospital based studies conducted previously, should be of lesser concern in this study, particularly due to its population based design. The colectomy rate of almost 10\% (10 of 102 patients) among controls within five years prior to the cancer diagnosis of the patient is an indication of the high internal validity, which further strengthens the hypoth- esis of surveillance colonoscopy having a protective effect against death from CRC.

Three major studies published in the 1990s further illustrate the problems of evaluating the effects of colonoscopy surveillance on CRC mortality. ${ }^{27-29}$ These studies are, in spite of their considerable size, difficult to interpret due to weaknesses such as different assessment of outcomes, the lack of suitable control groups and, above all, the hospital based design which does not permit generalisation of the results presented.

In an alternative approach, analytical survival models trying to maximise the basis for decision making for cancer risk in UC have been used. The results indicated a benefit of surveillance. $^{30} 31$ This mathematical approach to the problem has however been questioned as the results depend so critically on the underlying assumptions. ${ }^{32}$

The problems associated with surveillance programmes do not only concern the enrolment of patients but also the difficulties of keeping those patients on the programmes. Our study indicates that the majority of patients under surveillance undergo only one or at most two colonoscopies before leaving the programme; similar figures were found in the study from Leeds ${ }^{28}$ and to some extent by the report from St Mark's. ${ }^{27}$ This incomplete compliance is probably of vital importance, thus weakening the protective effect of colonoscopic surveillance and unfavourably distorting the results.

In conclusion, this case control study indicates that colonoscopic surveillance may be associated with a decreased risk of death from colorectal cancer.

The authors wish to thank Bahman Yektye Farahmand, BSc, for computer programming.

1 Edwards FC, Truelove SC. The course and prognosis of ulcerative colitis. Part IV. Carcinoma of the colon. Gut 1964;5:15-22.

2 Devroede GJ, Taylor WF, Saucer WG, et al. Cancer risk and life expectancy of children with ulcerative colitis. $N$ Engl $\mathcal{F}$ Med 1971;285:17-21.

3 Kewenter J, Ahlman H, Hultén L. Cancer risk in extensive ulcerative colitis. Ann Surg 1978;188:824-8.

4 Prior P, Gyde SN, Macartney JC, et al. Cancer morbidity in ulcerative colitis. Gut 1982;23:490-7.

5 Broström O, Löfberg R, Nordenvall B, et al. The risk of colorectal cancer in ulcerative colitis. Scand $\mathcal{f}$ Gastroenterol 1987;22:1193-9.

6 Gilat T, Fireman Z, Grossman A, et al. Colorectal cancer in patients with ulcerative colitis: a population study in central Israel. Gastroenterology 1988;94:870-7.

7 Gyde SN, Prior P, Allan RN, et al. Colorectal cancer in ulcerative colitis: a cohort study of primary referrals from ulcerative colitis: a cohort study of
three centres. Gut 1988;29:206-17.

8 Langholz E, Munkholm P, Davidsen M, et al. Colorectal cancer risk and mortality in patients with ulcerative colitis. Gastroenterology 1992;103:1444-51.

9 Ekbom A, Helmick C, Zack M, et al. Ulcerative colitis and colorectal cancer. A population based study. $N$ Engl $\mathcal{F}$ Med 990;323:1228-33.

10 Morson BC, Pang LSC. Rectal biopsy and precancer in ulcerative colitis. Gut 1967;8:423-34.

11 Lennard-Jones JE, Misiewicz JJ, Parrish JA, et al. Prospective study of outpatients with extensive colitis. Lancet 1974;i: 1065-7.

12 Connell WR, Lennard-Jones JE, Williams CB, et al. Factors affecting the outcome of endoscopic surveillance for cancer in ulcerative colitis. Gastroenterology 1994;107:934-44.

13 Rosenstock E, Farmer RG, Petras R, et al. Surveillance for colonic carcinoma in ulcerative colitis. Gastroenterology 1985;89:1342-6.

14 Löfberg R, Broström O, Karlén P, et al. Colonoscopic surveillance in long-standing total ulcerative colitis: a 15-year follow-up study. Gastroenterology 1990;99:102131 .

15 Rozen P, Baratz M, Fefer F, et al. Low incidence of significant dysplasia in a successful endoscopic surveillance pro- 
gram of patients with ulcerative colitis. Gastroenterology

1995;108:1361-70.
16 Collins RH Jr, Feldman M, Fordtran JS. Colon cancer, dysplasia, and surveillance in patients with ulcerative colitis: a critical review. N Engl F Med 1987;316:1654-8.

17 Gyde S. Screening for colorectal cancer in ulcerative colitis: dubious benefits and high costs. Gut 1990;31:1089-92.

18 Bernstein CN, Shanahan F, Weinstein WM. Are we telling patients the truth about surveillance colonoscopy in ulcerative colitis? Lancet 1994;343:71-4

19 Persson P-G, Bernell O, Leijonmarck C-E, et al. Survival and cause-specific mortality in inflammatory bowel disease: a population-based cohort study. Gastroenterology 1996;110:1339-45.

20 Ekbom A, Helmick C, Zack M, et al. Ulcerative colitis and colorectal cancer. A population based study. $N$ Engl f Med 1990;323:1228-33.

21 Nordenvall B, Broström O, Berglund M, et al. Incidence of ulcerative colitis in Stockholm County 1955-1979. Scand $\mathcal{F}$ Gastroenterol 1985;20:783-90.

22 Lunde AS. The person number system of Sweden, Norway, Denmark and Israel. Vital and health statistics. Series 2, Data evaluation and methods research. DHHS publication No. (PHS) 80-1358. Washington DC: US Government Printing Office, $1980 ; 84: 5-11$.

23 Mattsson B, Wallgren A. Completeness of the Swedish Cancer Register. Nonnotified cancer recorded on death certificates in 1978. Acta Radiol Oncol 1984;23:305-13.
24 Epicenter software. Epilog. Pasadena, California: Epicenter Software, 1984

25 Pinczowski D, Ekbom A, Baron J, et al. Risk factors for colorectal cancer in patients with ulcerative colitis: a case-control study. Gastroenterology 1994;107:117-20.

26 Moody GA, Jayanthi CSJ, Mac Kay H, et al. Long-term therapy with sulphasalazine protects against colorectal cancer in ulcerative colitis: a retrospective study of colorectal cancer risk and compliance with treatment in Leicestershire. Eur f Gastroenterol Hepatol 1996;8:1179-83.

27 Lennard-Jones JE, Melville DM, Morson BC, et al. Precancer and cancer in extensive ulcerative colitis: findings among 401 patients over 22 years. Gut 1990;31:800-6.

28 Lynch DAF, Lobo AJ, Sobala GM, et al. Failure of colonoscopic surveillance in ulcerative colitis. Gut 1993;34:107580

29 Choi PM, Nugent FW, Schoetz DJ Jr, et al. Colonoscopic surveillance reduces mortality from colorectal cancer in ulcerative colitis. Gastroenterology 1993;105:418-24.

30 Gage TP. Managing the cancer risk in chronic ulcerative colitis. A decision-analytic approach. $\mathcal{f}$ Clin Gastroenterol 1986;8:50-7.

31 Provenzale D, Kowdley KV, Arora S, et al. Prophylactic colectomy or surveillance for chronic ulcerative colitis? A decision analysis. Gastroenterology 1995;109:1188-96.

32 Lennard-Jones JE. Colitic cancer: supervision, surveillance or surgery? Gastroenterology 1995;109:1388-91. 